\title{
Trichoderma spp. Improve Growth of Arabidopsis Seedlings Under Salt Stress Through Enhanced Root Development, Osmolite Production, and $\mathrm{Na}^{+}$Elimination Through Root Exudates
}

\author{
Hexon Angel Contreras-Cornejo, Lourdes Macías-Rodríguez, Ruth Alfaro-Cuevas, and \\ José López-Bucio \\ Instituto de Investigaciones Químico-Biológicas, Universidad Michoacana de San Nicolás de Hidalgo, Edificio B3, Ciudad \\ Universitaria, C. P. 58030, Morelia, Michoacán, México
}

Submitted 11 September 2013. Accepted 24 January 2014.

Salt stress is an important constraint to world agriculture. Here, we report on the potential of Trichoderma virens and T. atroviride to induce tolerance to salt in Arabidopsis seedlings. We first characterized the effect of several salt concentrations on shoot biomass production and root architecture of Arabidopsis seedlings. We found that salt repressed plant growth and root development in a dose-dependent manner by blocking auxin signaling. Analysis of the wild type and eir1, aux1-7, arf7arf19, and tirlabf2abf19 auxinrelated mutants revealed a key role for indole-3-acetic acid (IAA) signaling in mediating salt tolerance. We also found that T. virens (Tv29.8) and T. atroviride (IMI 206040) promoted plant growth in both normal and saline conditions, which was related to the induction of lateral roots and root hairs through auxin signaling. Arabidopsis seedlings grown under saline conditions inoculated with Trichoderma spp. showed increased levels of abscissic acid, L-proline, and ascorbic acid, and enhanced elimination of $\mathrm{Na}^{+}$through root exudates. Our data show the critical role of auxin signaling and root architecture to salt tolerance in Arabidopsis and suggest that these fungi may enhance the plant IAA level as well as the antioxidant and osmoprotective status of plants under salt stress.

Salinity is a major environmental factor affecting crop production. Up to $7 \%$ of the total land surface is saline and approximately one-third of the world's irrigated land is subjected to secondary-induced salinization (Hariadi et al. 2011; Shabala and Cuin 2008). Under salt stress, plants experience dehydration, nutrient deficiencies, membrane dysfunction, and oxidative stress, which lead to tissue damage or early senescence (Essah et al. 2003; Katori et al. 2010).

To avoid accumulation of toxic sodium $\left(\mathrm{Na}^{+}\right)$levels in shoots, plants must take up no more than $3 \%$ of the $\mathrm{Na}^{+}$present in the rhizosphere, and many adaptive mechanisms are then activated (Zhang et al. 2008a). Salt tolerance is a complex

Corresponding author: J. López-Bucio; Telephone: +1 52 (443) 3265788, Fax: +1 52 (443) 3265788; E-mail: jbucio@umich.mx

* The $\boldsymbol{e}$-Xtra logo stands for "electronic extra" and indicates that two supplementary figures are published online and that Figures 1, 3, 6, and 7 appear in color online.

(C) 2014 The American Phytopathological Society trait that involves multiple physiological and biochemical mechanisms: for example, the salt-overly sensitive pathway, which regulates ionic homeostasis; the inducer of the CBF (Crepeat/dehydration-responsive element binding factor) expression and dehydration-responsive element-binding pathway that controls the expression of dehydration response element and $\mathrm{C}$ repeat-containing genes; and the mitogen-activated protein kinase cascade that regulates the generation of osmolytes and antioxidants with protective functions (Mehlmer et al. 2010; Seki et al. 2003; Xiong et al. 2002a and b; Zhu 2003).

The root system performs indispensable plant functions such as uptake of nutrients and water, anchorage in the soil, and interaction with symbiotic microorganisms (López-Bucio et al. 2003, 2005). Consequently, root system development is central for the plant to reach optimal growth and directly contributes to the levels of yield obtained in crops. The impact of the root on plant growth has become apparent not only in model plants such as Arabidopsis thaliana, Medicago truncatula, and Lotus japonicus but also in important crops such as wheat (Triticum aestivum), rice (Oryza sativa), and maize (Zea mays) (Coudert et al. 2010; Hochholdinger and Tuberosa 2009). One way to minimize the negative impact of biotic and abiotic factors on yield is to manipulate root system architecture (RSA). The basic aspects of root architecture involve primary root growth and lateral and adventitious root formation. Branching structures are covered by root hairs $(\mathrm{RH})$, a class of differentiated epidermal cells that further increase the exploratory potential. The primary root originates in the embryo and produces many lateral roots (LR) during vegetative growth, and each of these will produce more LR (Casimiro et al. 2003; López-Bucio et al. 2005; Malamy and Benfey 1997).

RSA is modified by the endogenous auxin level or in response to environmental factors that increase the auxin pool in the plant or affect auxin sensitivity (Himanen et al. 2002; LópezBucio et al. 2003; Pérez-Torres et al. 2008). In Arabidopsis, salt stress induces nitrilase genes NIT1 and NIT2, which are involved in indole-3-acetic acid (IAA) biosynthesis (Bao and Li 2002). In addition, Wang and associates (2009) reported that high salt exposure suppresses LR initiation and organogenesis, which correlated with the concomitant reduction of expression of the auxin-inducible reporter $D R 5:: G U S$ in primary root tips. These results suggest that auxin homeostasis is important for adaptive root system development under salt stress; however, it still remains to be determined whether auxin biosynthesis, transport, or sensitivity is the key target of salt stress. Other- 
wise, the ability of plants to adapt to stress conditions often appears to depend on their association with microbes. Recent reports have shown that auxin-like signals produced from rhizosphere microorganisms could improve root branching in Arabidopsis, with a dramatic impact in plant biomass production (Ortiz-Castro et al. 2011). The potential of plant-associated microorganisms to produce IAA, auxin precursors, or auxin signal mimics represents a means to influence the endogenous auxin pool of the host (Contreras-Cornejo et al. 2009; Felten et al. 2012; Hilbert et al. 2012). However, little is known about the implication of this hormone in symbiosis or plant tolerance to stress.

Trichoderma spp. are free-living fungi that are common in soil and root ecosystems. They have been widely studied for their capacity to produce antibiotics, parasitize other fungi, and compete with deleterious plant microorganisms (Harman et al. 2004). Until recently, these traits were considered to be the basis for how Trichoderma spp. exert beneficial effects on plant growth and development. However, it is clear that certain species also have substantial direct influence on plant health and development by producing phytohormones, activating defense responses, or conferring stress tolerance in plants (Brotman et al. 2013; Contreras-Cornejo et al. 2009, 2011, 2013; Velázquez-Robledo et al. 2011). Trichoderma spp. allowed the accumulation of proline in wheat plants under salt stress condition (Rawat et al. 2011), and microarray analysis of Arabidopsis and cucumber roots exposed to salt stress and inoculated with Trichoderma spp. revealed an increased expression of genes related to salt-tolerance, osmoprotection processes, and ascorbic acid (AA) production (Brotman et al. 2013).

Our previous research showed that Trichoderma virens and T. atroviride produce IAA and the indolic compounds indole3-ethanol, indole-3-acetaldehyde, and indole-3-carboxaldehyde as part of their metabolism (Contreras-Cornejo et al. $2009,2011)$. It was found that mutations in genes involved in auxin transport or signaling $(A U X 1, B I G, E I R I$, and $A X R 1)$ reduced the growth-promoting and root developmental effects of Trichoderma spp. inoculation. Colonization of plant roots by fungal hyphae activated DR5:uidA expression, which correlated with an increased cell proliferation in LR tips. Application of all three indolic compounds produced by the fungus to

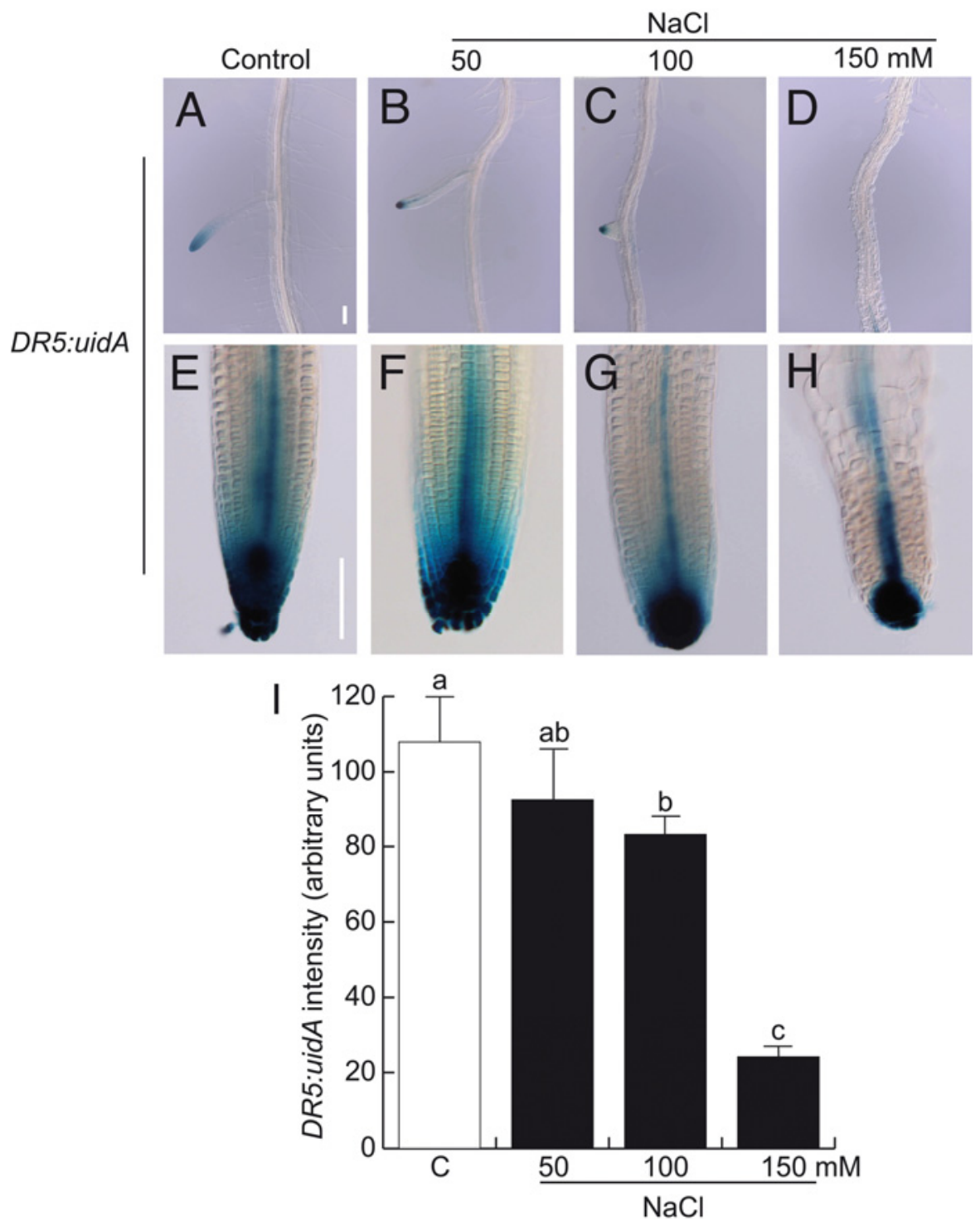

Fig. 1. Effect of $\mathrm{NaCl}$ on DR5: uidA expression. Representative photographs of $\mathbf{A}$ to $\mathbf{D}$, lateral roots or $\mathbf{E}$ to $\mathbf{H}$, primary root tips from transgenic Arabidopsis seedlings expressing the DR5:uidA auxin-inducible gene marker, which were grown on media with increasing concentrations of NaCl. I, Quantitative analysis of $\beta$-glucuronidase expression in primary root tips using the image $\mathrm{J}$ program. Photographs are representative individuals of at least 15 plants stained. Scale bar $=1 \mathrm{~mm}$. The experiment was repeated two times with similar results. 
Arabidopsis seedlings showed a dose-dependent effect on biomass production and in activation of DR5:uidA expression.

In this report, we show that salt affects plant biomass production and reduces root growth, LR formation, and RH development by decreasing auxin responsiveness. Cocultivation of plant roots with $T$. virens or $T$. atroviride normalized root development, likely because these fungi provide IAA to plants. Moreover, Trichoderma spp. improved the antioxidative and osmoprotective capacity and increased growth. Our results reveal that, by enhancing LR and RH development through sustained auxin production, Trichoderma spp. may affect plant performance and yield under saline conditions.

\section{RESULTS}

Salinity affects root architecture and decreases auxin responsiveness in Arabidopsis seedlings.

A common negative effect of salinity is reduced root growth and decreased plant biomass (Achard et al. 2006). Little is known about specific root architectural responses to salt and the contribution of auxin signaling in the different traits responsible for root adaptation to this stress. To evaluate the effect of salt on Arabidopsis growth and development, wildtype (WT) (Col-0) seedlings were germinated and grown for 9 days on vertically oriented agar plates containing $0.2 \times$ Murashige and Skoog (MS) medium supplied with increasing concentrations of salt ( 50 to $200 \mathrm{mM} \mathrm{NaCl}$ ). It was found that increasing salt concentration in the medium affected total fresh weight, primary root length, LR number and density, and RH length in a dose-dependent manner (Supplementary Fig. S1A to $\mathrm{E})$. These effects were more evident in seedlings grown in 100 to $150 \mathrm{mM}$ or higher salt concentrations, which drastically decreased plant growth and biomass production. At $150 \mathrm{mM}$ $\mathrm{NaCl}, \mathrm{LR}$ and RH formation was totally blocked (Supplementary Fig. S2). These results show that $\mathrm{NaCl}$ affects fundamental cellular processes responsible for the configuration of RSA.

To test whether the repression of root branching by $\mathrm{NaCl}$ could be associated with changes in auxin accumulation or
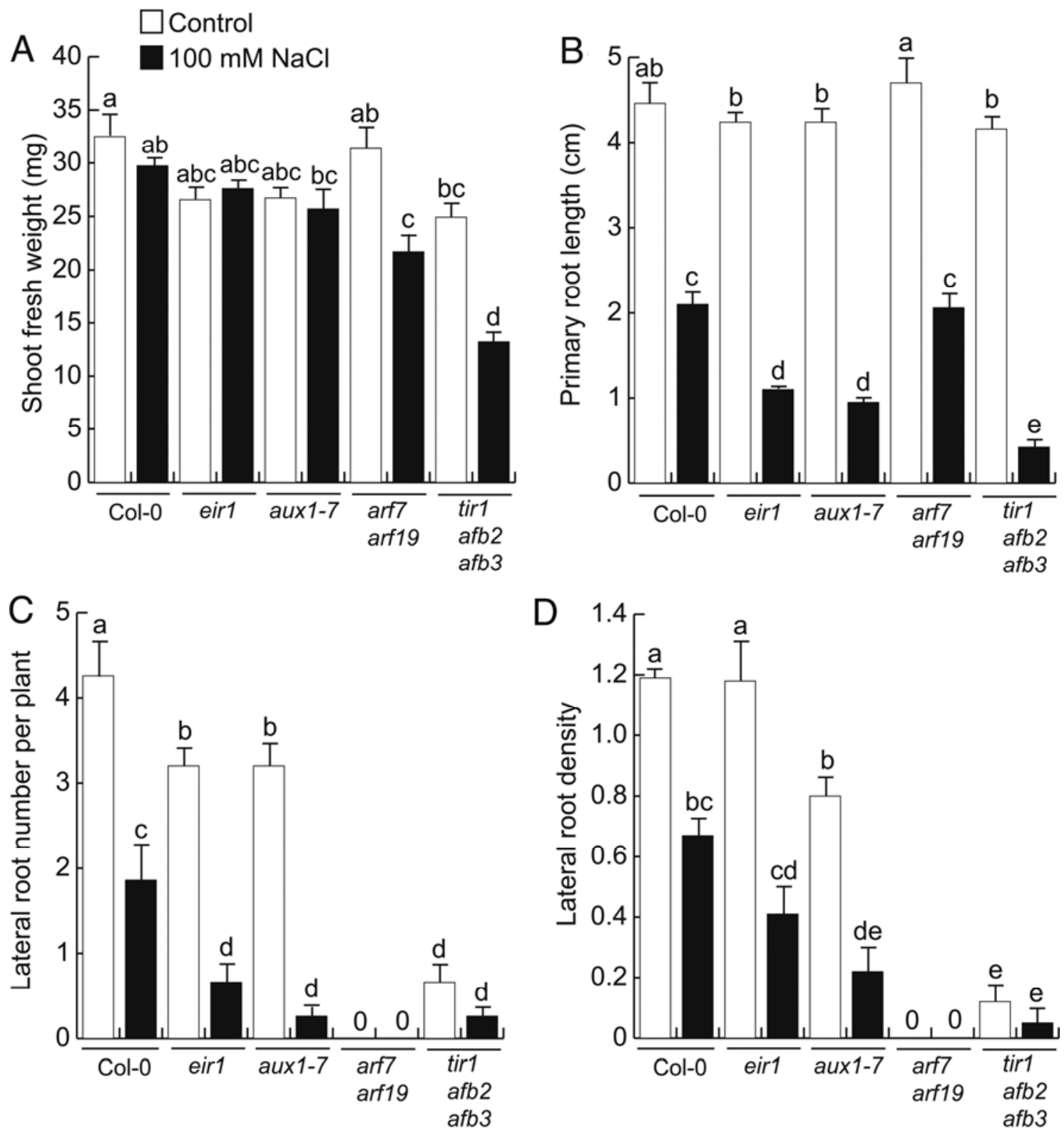

Fig. 2. Effect of $\mathrm{NaCl}$ on Arabidopsis wild type and mutants with defects in auxin transport or signaling. A, Shoot fresh weight. B, Primary root length $(n=$ 15). C, Lateral root number per plant $(n=15)$. D, Lateral root density $(n=15)$. Error bars represent the standard deviation. Different letters are used to indicate means that differ significantly $(P<0.05)$. The experiment was repeated three times with similar results. 
response, expression of the $\beta$-glucuronidase (GUS) reporter gene driven by the auxin-sensitive $D R 5$ promoter (Dubrovsky et al. 2008; Ulmasov et al. 1997) was examined in primary roots and LR. It was found that 50 to $150 \mathrm{mM} \mathrm{NaCl}$ affected the expression of DR5:uidA in primary roots and LR (Fig. $1 \mathrm{~A}$ to $\mathrm{H}$ ), which correlated with decreased root branching. The intensity of DR5:uidA gene expression was determined from images of primary root tips, which were processed using the Image $\mathbf{J}$ software and the data expressed as arbitrary units (Fig. 1I). These data show that salt inhibits auxininducible gene expression in a dose-dependent manner in primary root tips.

\section{Arabidopsis mutants defective} on auxin receptors are oversensitive to salt treatments.

Previous work showed that Arabidopsis mutants with defects in auxin influx (aux1-7) or efflux (pin2) were slightly oversensitive to salt stress, indicating that auxin transport might play a role in root system remodeling under salt stress (Wang et al. 2009). To further characterize the contribution of auxin transport and response in plant salt tolerance and its relationship with root adaptive traits, we compared the growth and development of WT and Arabidopsis mutants, including eirl-1 and aux1-7, defective on auxin transporters, and arf7arf19 and tirlafb2afb3, defective in transcription factors or receptors involved in auxin response, respectively. When grown under $100 \mathrm{mM} \mathrm{NaCl}$, it was found that the eirl-1 and aux 1-7 mutants showed a slight decrease of shoot fresh weight under salt treatment in a manner similar to WT seedlings. Interestingly, the $\operatorname{arf7arf19}$ and tirlafb2afb3 mutants were clearly oversensitive to this salt treatment, with a 35 and $50 \%$ inhibition in shoot fresh weight, respectively (Fig. 2A). Salt treatment repressed approximately 55 to $60 \%$ of primary root growth, LR number per plant, and LR density in WT seedlings; whereas, in eirl, auxl-7, and tirlafb2afb3, these root architectural traits were more severely affected (Fig. 2B to D). The fact that the tirlafb2afb3 triple mutant, which is defective in three putative auxin receptors of the TIR1 family, shows salt oversensitivity in biomass production and primary root growth suggests that auxin signaling (and not only auxin transport) is an important target of salinity.

\section{T. virens and T. atroviride show differential growth and produce auxin under salt stress.}

High salinity may affect plants, their microbial partners, and the outcome of the plant-microbe interaction. We next determined the effect of salinity on growth of $T$. virens and $T$. atroviride. In all, $10^{6}$ conidia from each species were germinated and grown for 5 days on agar plates containing $0.2 \times$ MS medium supplied with increased concentrations of salt (50 to $300 \mathrm{mM} \mathrm{NaCl}$ ). It was found that salt affected the growth of both Trichoderma spp. in a dose-dependent manner (Fig. 3A). However, both fungal strains tolerated $150 \mathrm{mM}$ $\mathrm{NaCl}$ well (Fig. 3B and $\mathrm{C}$ ) and differential effects were observed with the $300 \mathrm{mM}$ salt treatment, in which the growth of $T$. virens and $T$. atroviride was repressed 27 and $74 \%$, respectively. These results show that $T$. virens tolerates higher $\mathrm{NaCl}$ levels than $T$. atroviride and may represent a very promising agent to test salt responses in plant-fungus interactions.

Trichoderma spp. release auxin and auxin precursors as part of their metabolism (Contreras-Cornejo et al. 2009); thus, it was important to know whether salinity could affect auxin production in these fungi. The production of IAA by $T$. virens and T. atroviride was determined in liquid medium with or without $100 \mathrm{mM} \mathrm{NaCl}$, a salt concentration that drastically affects LR formation in Arabidopsis. It was found that salt slightly increased IAA production in $T$. virens from 4.21 to $5.88 \mathrm{ng} / \mathrm{ml}$, whereas in T. atroviride, a higher and sustained auxin production from 7.65 to $7.64 \mathrm{ng} / \mathrm{ml}$ was registered under both normal and saline growth conditions. These data show that Trichoderma spp. are able to produce auxin when subjected to salt treatment, which could benefit plant growth under salt stress.

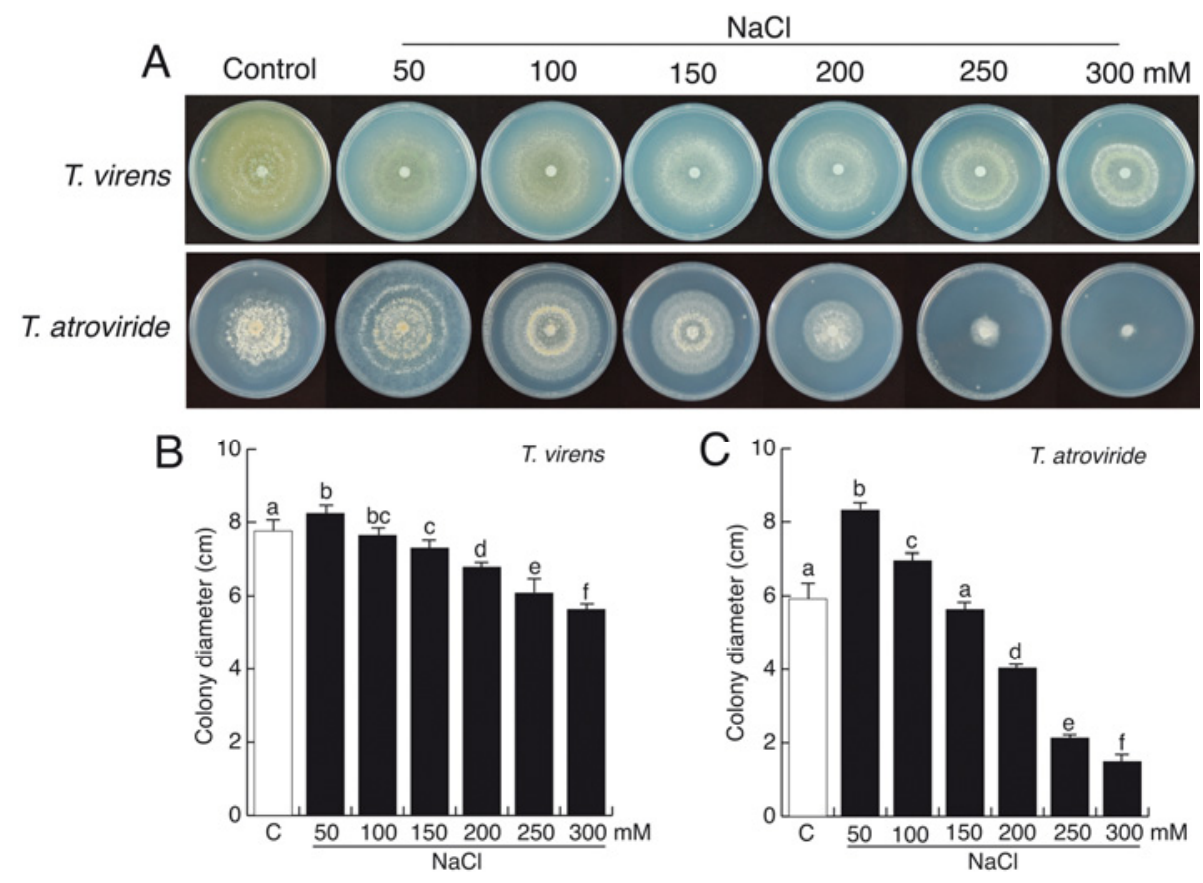

Fig. 3. Effect of $\mathrm{NaCl}$ on Trichoderma spp. growth. To determine the effect of $\mathrm{NaCl}$ on fungi, $1 \times 10^{6}$ spores from Trichoderma spp. were used to inoculate $0.2 \times$ Murashige and Skoog medium with or without $\mathrm{NaCl}$. A, Representative photographs showing the aspect of the colonies of the strains grown at $24^{\circ} \mathrm{C}$ and photographed after 5 days. B, Kinetic of Trichoderma virens growth determined by measuring colony diameter. C, Kinetic of $T$. atroviride growth. Bars represent the means \pm standard deviation, based on two independent experiments with three petri dishes each. Different letters represent means statistically different at the 0.05 level. 
Trichoderma spp. promote growth and confer salt tolerance in Arabidopsis.

To investigate whether Trichoderma spp. could confer salt tolerance to plants, Arabidopsis (Col-0) seedlings were germinated and grown on petri plates containing agar-solidified $0.2 \times$
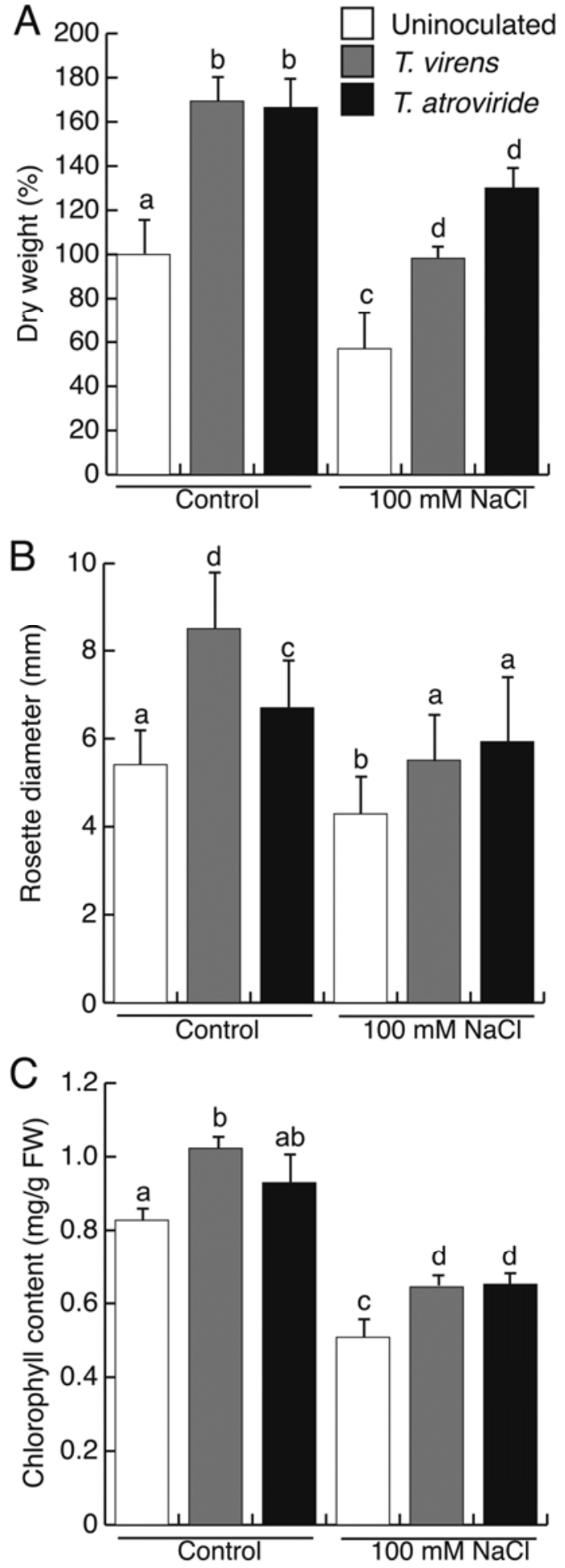

Fig. 4. Trichoderma spp. confer salt tolerance in Arabidopsis. A, Effect of Trichoderma spp. on total biomass accumulation represented as dry weight. B, Shoot diameter $(n=60)$. C, Total chlorophyll content. Rosettes were excised after 5 days of inoculation and chlorophyll content was determined. Values shown represent means of six groups of 20 seedlings \pm standard error. Asterisks are used to indicate means that differ significantly $(P<0.05)$. The experiment was repeated three times with similar results.
MS medium with or without $100 \mathrm{mM} \mathrm{NaCl}$. At 4 days after germination, the seedlings were treated with sterilized water (control treatment) or with $10^{6}$ conidia of $T$. virens or $T$. atroviride. Fungal spores were placed at a $5-\mathrm{cm}$ distance from the primary root tip to test the possibility that auxins released by the fungal colony could reach the root system and affect growth and development.

Plants inoculated with $T$. virens or $T$. atroviride showed enhanced shoot growth when compared with control seedlings when grown in medium with or without $100 \mathrm{mM}$ salt. The dif-
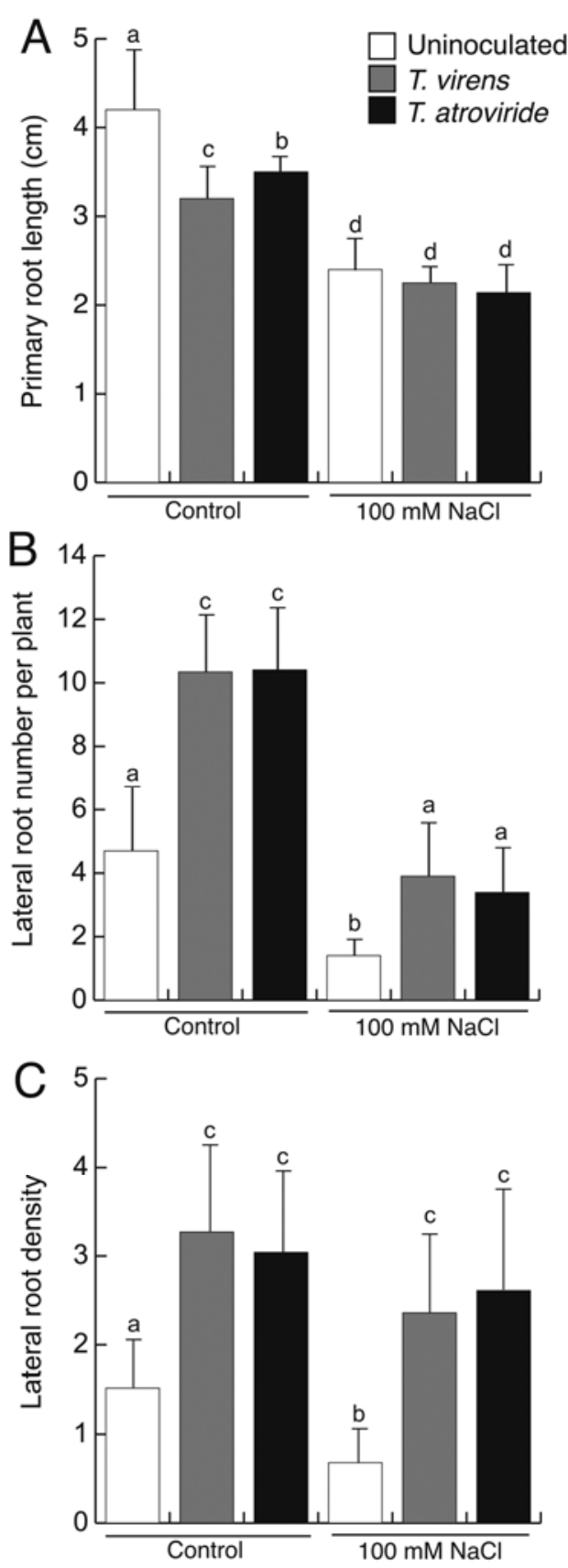

Fig. 5. Effects of Trichoderma spp. on root architecture of Arabidopsis seedlings grown under salinity. Seedlings were germinated and grown for 5 days on the surface of agar plates containing $0.2 \times$ Murashige and Skoog medium. Plates were inoculated with Trichoderma virens or T. atroviride at a distance of $5 \mathrm{~cm}$ from the primary root tip and grown for an additional 5-day period. A, Primary root length. B, Lateral root number per plant. C, Lateral root density. Bars represent the means \pm standard deviation, based on three independent experiments with 60 seedlings each. Different letters represent means statistically different at the 0.05 level. 
ference in dry weight and rosette diameter clearly demonstrated the beneficial effects of these fungi under salt stress (Fig. 4A and B). Saline stress also had a negative effect on chlorophyll content. The content of chlorophyll in plants grown with 100 $\mathrm{mM} \mathrm{NaCl}$ decreased by $38.56 \%$ when compared with the control treatment. However, the chlorophyll level increased by $15.66 \%$ in plants inoculated with $T$. virens and $16.87 \%$ by $T$. atroviride (Fig. 4C). These results show the beneficial effects of Trichoderma spp. to confer salt tolerance.

\section{Trichoderma spp. improve root-system architecture} of Arabidopsis seedlings grown under saline conditions.

The mechanisms by which plants incorporate microbial signals into root-system development under saline stress are poorly understood. We performed bioassays to determine whether Trichoderma spp. could affect root plasticity in Arabidopsis grown under salt stress. We found that seedlings grown in normal conditions or with $100 \mathrm{mM} \mathrm{NaCl}$ co-cultivated with $T$. virens or $T$. atroviride developed a more branched root system. There were slight differences in primary root growth in Trichoderma spp.-inoculated seedlings when compared with axenically grown seedlings. Salt stress repressed by $50 \%$ primary root growth in control or inoculated seedlings (Fig. 5A). As expected, the LR number and density (LR number per centimeter) were reduced by $100 \mathrm{mM}$ salt treatment. Interestingly,
Trichoderma spp. normalized LR formation, increasing both LR number and density to the levels shown in uninoculated seedlings grown without salt (Fig. 5B and C). These results show that Trichoderma spp. can normalize root branching in Arabidopsis under salt stress.

$\mathrm{RH}$ are specialized tubular structures formed from differentiated epidermal cells of roots called trichoblasts. To investigate the effect of Trichoderma spp. on $\mathrm{RH}$ formation under elevated salinity, Arabidopsis seedlings were germinated and grown for 4 days on $0.2 \times$ MS with or without salt; after this period, seedlings were treated with water as a control or inoculated with Trichoderma spp. and grown for 5 additional days. Both RH length and density decreased significantly with 100 $\mathrm{mM} \mathrm{NaCl}$ (Fig. 6G and H). Importantly, Trichoderma spp. increased the RH length and density in Arabidopsis grown in normal or saline conditions when compared with their respective controls (Fig. 6A to H). These data show that Trichoderma spp. can promote RH length and density.

\section{Trichoderma spp. increase auxin-inducible gene expression} in Arabidopsis under salt stress.

The results described above strongly suggest that Trichoderma spp. induce LR formation under salt stress, likely providing auxin to plants. Because auxin triggers various developmental effects through the activation of auxin-responsive
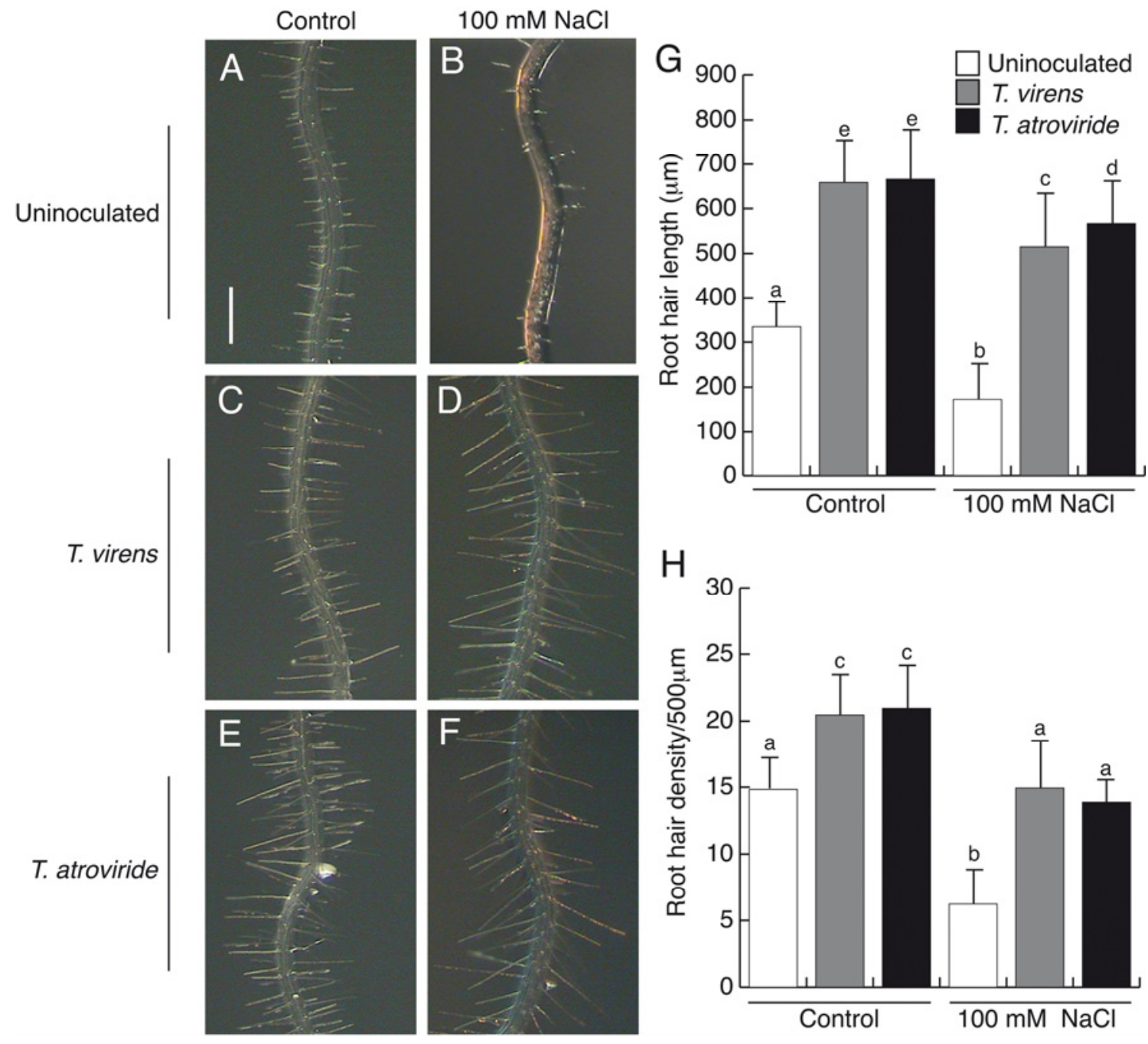

Fig. 6. Effect of Trichoderma spp. on root-hair development in Arabidopsis seedlings grown under salt stress. A to F, Representative photographs of root hairs from seedlings grown in normal or saline conditions and inoculated with Trichoderma spp. Bar $=500 \mu \mathrm{m}$. G, Length of root hairs formed in the primary root and $\mathbf{H}$, root-hair density. Values shown represent the mean of 100 root hairs \pm standard deviation. Different letters are used to indicate means that differ significantly $(P<0.05)$. 
genes, we evaluated the expression of the auxin-responsive marker gene DR5:uidA. T. virens and T. atroviride increased the expression of DR5:uidA in LR and primary root tips in nonsaline conditions (Fig. 7A to F). Although expression of DR5:uidA was reduced in plants treated with $100 \mathrm{mM} \mathrm{NaCl}$, both Trichoderma spp. clearly induced the expression of DR5:uidA in LR and primary root tips under elevated salinity (Fig. 7G to L), which correlated with an improved growth of LR. An analysis of the DR5:uidA expression domain in primary root tips processed using the Image $\mathbf{J}$ software showed that $T$. virens and $T$. atroviride increased auxin-responsive gene expression by $40 \%$ (Fig. 7M). These results show that Trichoderma spp. increase auxin-responsive gene expression under saline stress, which positively affect LR development.

\section{Trichoderma spp. increase abscissic acid, L-proline,}

\section{AA content, and salt exudation.}

To determine the biochemical and metabolic events that occur in Arabidopsis during the interaction with Trichoderma spp. under saline or normal conditions, we quantified the amounts of metabolites related to salt stress. Abscissic acid (ABA) is considered the universal plant stress hormone (Verslues and Zhu 2005; Wasilewska et al. 2008). Arabidopsis seedlings inoculated with $T$. virens or $T$. atroviride showed a twofold increased ABA concentration in shoots when compared with axenically grown seedlings. ABA levels in uninoculated plants were sixfold increased in response to saline stress. Interestingly, plants subjected to $100 \mathrm{mM} \mathrm{NaCl}$ treatment and inoculated with Trichoderma spp. displayed similar levels of ABA compared with nonstressed plants (Fig. 8A). L-proline (L-Pro) is accumulated in response to salinity, and its accumulation frequently correlates with tolerance to drought or salt stress in plants (Ben et al. 2008; Parida et al. 2008). Saline stress induced twofold the amount of L-Pro in uninoculated seedlings when compared with nonstressed seedlings, and a further increase in L-Pro was evident in Arabidopsis seedlings inoculated with Trichoderma spp. (Fig. 8B). Several reports have suggested that AA has a crucial function as antioxidant. Arabidopsis seedlings inoculated with $T$. virens grown under nonsaline conditions showed increased AA levels when compared with uninoculated seedlings. No changes were found in seedlings inoculated with T. atroviride. In contrast, the AA amounts in Arabidopsis under salt-stress inoculated with Trichoderma spp. increased further when compared with the saline control (Fig. 8C).

Excessive $\mathrm{Na}^{+}$accumulated in plant cells is the primary cause of inhibition of plant growth (Ghoulam et al. 2002; Ungar 1996). Because detoxification mechanisms would prevent salt toxicity, we determined whether Trichoderma spp. inoculation could affect the levels of $\mathrm{Na}^{+}$in root exudates. Seedlings were grown in normal or saline conditions and inoculated with Trichoderma spp. by 5 days. Then, seedlings were transferred to falcon tubes containing tridistilled water. Root exudates were collected 2 days later, samples were filtered and $\mathrm{Na}^{+}$was determined by atomic absorption spectrophotometry. In plants grown in medium without salt, no significant differences in $\mathrm{Na}^{+}$exudation were found among treatments. However, plants grown under salinity increased exudation of $\mathrm{Na}^{+}$by roots, with a clearly enhanced amount of $\mathrm{Na}^{+}$being exuded in Trichoderma spp.inoculated plants (Fig. 8D). These data show that Arabidopsis seedlings inoculated with Trichoderma spp. are better adapted to cope with salt stress, likely by increasing plant vigor, osmolite and antioxidant production, and salt exudation.

\section{DISCUSSION}

Plants synthesize and require a variety of signals to adjust growth and development throughout their life cycle. Auxins,
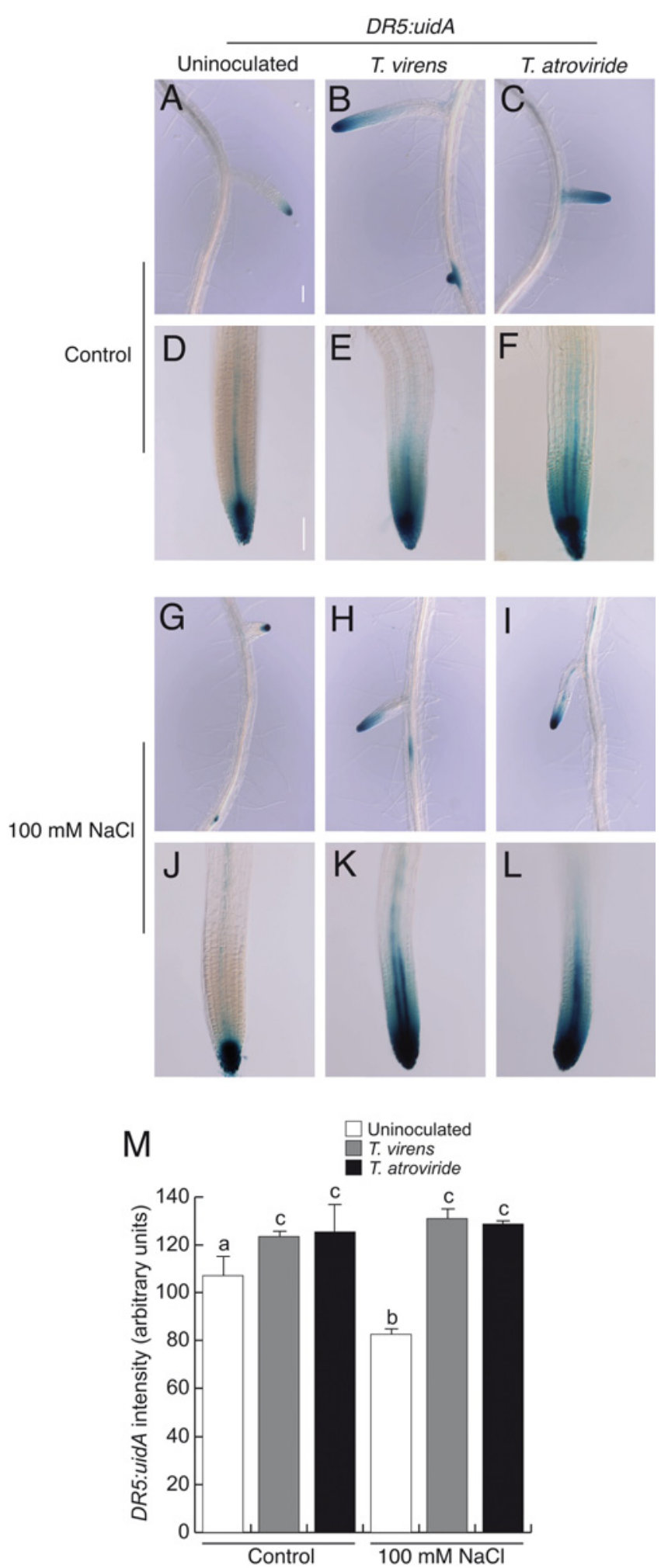

Fig. 7. Effect of Trichoderma spp. on the expression of DR5:uidA in normal or saline growth conditions. Arabidopsis transgenic seedlings were grown by 4 days on agar plates containing $0.2 \times$ Murashige and Skoog medium with or without $100 \mathrm{mM} \mathrm{NaCl}$ and inoculated with Trichoderma spp. by 5 days. A to $\mathbf{F}$, Representative images from DR5.uidA seedlings uninoculated or inoculated with Trichoderma spp. in normal conditions. G to $\mathbf{L}$, Photographs from seedlings uninoculated or inoculated with Trichoderma spp. under elevated salinity. M, Quantitative analysis of $\beta$-glucuronidase expression in primary root tips using the image $\mathbf{J}$ program. Photographs are representative individuals of at least 15 plants stained. Scale bar $=100 \mu \mathrm{m}$. The experiment was repeated three times with similar results. 
including IAA, comprise a group of tryptophan-derived signals which are involved in most aspects of plant development (Woodward and Bartel 2005) These compounds exert a strong biological activity at very low concentrations in both in vivo and in vitro systems. Optimal plant growth requires tight control of IAA activity, which is accomplished by diverse mechanisms that include IAA biosynthesis, its transport among tissues, cycling between active and inactive forms, and signal perception through a family of auxin transporters, transcription factors, and IAA receptors (Leyser 2006; Ljung et al. 2002; Mockaitis and Estelle 2008). Auxins have also been implicated in an abiotic stress response (Bao and $\mathrm{Li}$ 2002). Recent breeding improvements in terms of salt resistance of maize have led to a genotype with improved growth under saline conditions. By comparing this salt-resistant hybrid with a sensitive hybrid, it was possible to show differences in hormone concentrations in expanding leaves and roots. In response to salinity, the saltresistant maize significantly increased indole-butyric acid concentrations in leaves and maintained IAA concentration in roots (Zörb et al. 2013). These hormonal adaptations were suggested to activate $\beta$-expansin gene expression to maintain growth of resistant maize hybrids under salt stress. Moreover, ABA concentrations significantly increased in resistant maize leaves under salt stress, which may contribute to acidifying the apoplast which, in turn, is a prerequisite for growth (Zörb et al. 2013). In consonance with this information, it was reported that auxin transport is required for remodeling RSA under salt stress because aux1-7 and pin2 Arabidopsis mutants showed slight oversensitivity to salt exposure and because salt treatments repress expression of the auxin efflux carrier PIN2, and led to a stable reduction in PIN2 protein abundance (GalvanAmpudia and Testerink 2011; Wang et al. 2009).

Despite this available information, little is known about the relationship between salinity stress and auxin levels in plants and the role of auxin in alleviating salt stress. Our data further extend these previous observations by showing that auxin responsiveness is an important target of salinity, because $\mathrm{NaCl}$ treatments decrease biomass production, root growth, and LR formation in Arabidopsis seedlings, which correlates with a dose-dependent reduction of auxin-inducible gene expression (Fig. 1). The genetic analysis of growth and root architectural responses of the WT and eirl, auxl-7, arf7arf19, and tirlabf2abf 19 auxin-related mutants further supports the hypothesis that an intact auxin signaling pathway and not only auxin transport is required for salt tolerance, because arf7arf19 and tirlabf $2 a b f 19$ were the most sensitive of the mutants tested regarding salt repression of growth (Fig. 2).

The use of plant symbionts is a promising strategy for agriculture sustainability because they improve plant health under different conditions. For instance, the root endophytic basidiomycete Piriformospora indica increased resistance against biotic stress and tolerance to abiotic stress in many plants. Root
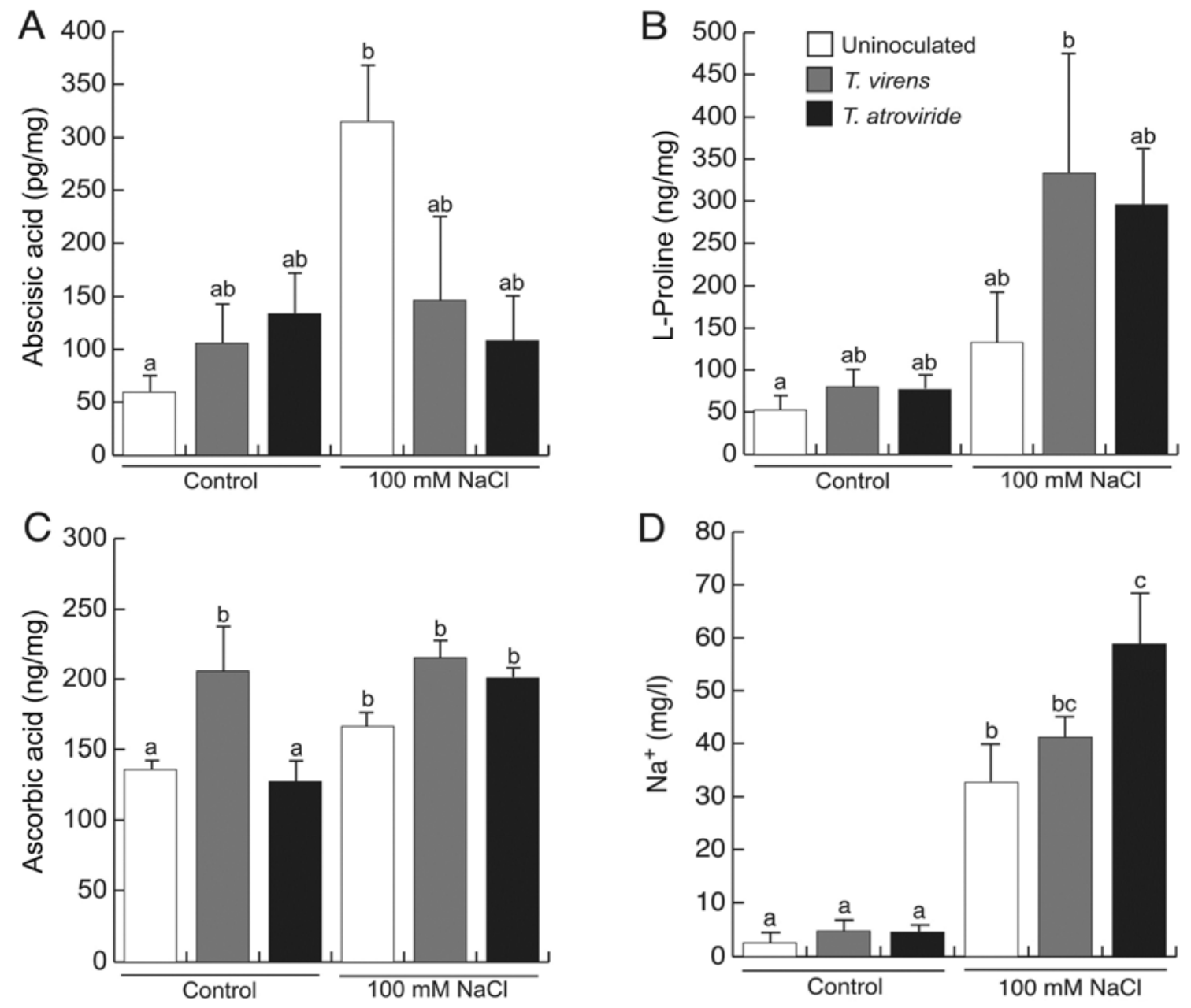

Fig. 8. Effects of Trichoderma spp. on biochemical changes and $\mathrm{Na}^{+}$elimination through root exudates. Metabolite determination was performed after 5 days of fungal inoculation. A, Endogenous content of cis, trans-abscisic acid (ABA). B, Content of free L-proline. C, Content of ascorbic acid. D, Root exudates were collected by 2 days from 9-day-old Arabidopsis maintained hydroponically. Aqueous $\mathrm{Na}^{+}$was determined by atomic absorption spectrophotometry ( $n=3$ ). Error bars represent the standard error. Different letters are used to indicate means that differ significantly $(P<0.05)$. The experiment was repeated four times with similar results. 
colonization by $P$. indica increased plant growth and attenuated the $\mathrm{NaCl}$-induced lipid peroxidation, metabolic heat efflux, and fatty acid desaturation in leaves of the salt-sensitive barley 'Ingrid'. In addition, $P$. indica significantly elevated the amount of AA and increased the activities of antioxidant enzymes in barley roots under salt stress conditions. Likewise, a sustained upregulation of the antioxidative system was demonstrated in NaCl-treated roots of the salt-tolerant barley 'California Mariout' (Waller et al. 2005). These findings suggest that antioxidants might play a role in both inherited and endophyte-mediated plant tolerance to salinity.

T. virens and T. atroviride were found to produce IAA and auxin-related substances, which may normalize root growth under salinity stress. Arabidopsis and cucumber (Cucumis sativus L.) plants treated with Trichoderma spp. prior to salt stress show significantly improved seed germination (Brotman et al. 2013). In addition, Trichoderma spp. modulated the expression of several genes related to osmo-protection and general oxidative stress in roots of both plant species. The MDAR gene coding for monodehydroascorbate reductase was significantly upregulated and, accordingly, the pool of reduced AA was increased in Trichoderma spp.-treated plants. Therefore, it was interesting to examine whether $T$. virens or $T$. atroviride could contribute to salt tolerance in Arabidopsis seedlings via auxin production or through other mechanisms. We found that both Trichoderma spp. tested were able to sustain prolific growth at $150 \mathrm{mM} \mathrm{NaCl}$. However, a differential salt response was found because, at greater salt concentrations, $T$. virens was more halotolerant than T. atroviride (Fig. 3). Importantly, T. virens and $T$. atroviride were able to produce IAA when grown in medium supplied with $100 \mathrm{mM} \mathrm{NaCl}$ or even greater IAA levels than those quantified in medium without salt, suggesting their great potential as plant growth-promoting fungi to cope with salinity in crops.

In Arabidopsis seedlings cocultivated with $T$. virens or $T$. atroviride, there were an increased number of LR, RH, and biomass accumulation (Figs. 4 to 6). RH development is a useful marker of differentiation processes that take place in the root (López-Bucio et al. 2005). It has been reported that $\mathrm{NaCl}$ treatment inhibits RH growth (Halperin et al. 2003). In contrast, Trichoderma spp. increased both RH number and length (Fig. 6). These data suggest that root plasticity could be part of a mechanism by which Trichoderma spp. can confer salt tolerance to plants. In Arabidopsis and other plant species, exogenous auxin application can induce both LR and RH formation (Laskowski et al. 1995); therefore, we speculated that, by providing auxins, Trichoderma spp. could restore auxin homeostasis and, consequently, growth and development could be normalized when grown under stressing salt levels. To verify this, the effect of cocultivation with Trichoderma spp. on DR5:uidA expression was tested under salinity. It was found that $T$. virens or $T$. atroviride could increase the expression of DR5:uidA in LR and that more of these structures were formed in response to fungal interaction (Fig. 7). Therefore, it is tempting to speculate that auxins derived from Trichoderma spp. may be important to sustain root developmental programs under saline stress. A key role for IAA in plant salt tolerance induced by fungi has started to be revealed. For example, Redman and associates (2011) reported that Fusarium culmorum and Curvularia protuberata enhanced growth of rice plants under salinity. Similarly, the endophytic fungi Phoma glomerata and Penicillium sp. significantly increased plant biomass of cucumber under saline stress (Waqas et al. 2012). A Streptomyces sp. isolate increased the growth and development of wheat plants in normal and saline conditions. This isolate also produced IAA in axenic conditions, which increased when salt was added (Sadeghi et al. 2012). Thus, plant-growth- promoting fungi may be advantageous to plants grown under salt stress by producing auxins.

Salt tolerance is a complex trait involving the coordinated action of many gene families that perform a variety of functions such as control of water loss through stomata, ion sequestration, metabolic and osmotic adjustments, and antioxidative protection (Abogadallah 2010). For example, under severe saline stress, reactive oxygen species (ROS) production can damage cell components (Mittler 2002). The osmoprotectant L-Pro is accumulated in many plant species in response to drought and salinity, and its accumulation frequently correlates with stress tolerance. This amino acid functions as a scavenger of hydroxyl radicals, controlling redox homeostasis (Ben et al. 2008; Fabro et al. 2004). Another potent antioxidant molecule is AA, which detoxifies ROS, particularly hydrogen peroxide (Smirnoff 2000). Here, we show that Trichoderma spp.induced plant salt tolerance in Arabidopsis is correlated with increases in L-Pro and AA (Fig. 8). Roots secrete many substances which include ions, free oxygen and water, enzymes, mucilage, and a diverse array of carbon-containing primary and secondary metabolites (Bais et al. 2006). Root exudates are transported across the cellular membrane and secreted into the surrounding rhizosphere. $\mathrm{Na}^{+}$toxicity is considered one of the most important factors limiting root growth (Ghoulam et al. 2002; Ungar 1996) and, therefore, it is expected that exclusion or detoxification mechanisms might be integral to plant adaptation to salinity. We tested whether Trichoderma spp. induced the $\mathrm{Na}^{+}$elimination through root exudates as part of a plant detoxification mechanism. The content of $\mathrm{Na}^{+}$exudated from roots grown in normal conditions was similar among treatments (Fig. 8D). In contrast, uninoculated seedlings grown under salinity exuded an enhanced amount of $\mathrm{Na}^{+}$when compared with nonstressed plants. Importantly, the $\mathrm{Na}^{+}$exuded by roots was increased by 25.76 and $79.65 \%$ when cocultivated with $T$. virens or $T$. atroviride, respectively. These effects may allow plants to better tolerate excess $\mathrm{Na}^{+}$levels. One possibility to explain the increased production of osmolite, antioxidants, and $\mathrm{Na}^{+}$exclusion is that the beneficial effects of Trichoderma spp. in roots through increasing the auxin pool improves plant health and activates metabolic or transport processes, which lead to an improved capacity to react or adapt to salt stress.

In conclusion, our research demonstrates the beneficial role of Trichoderma spp. to improve saline stress tolerance in Arabidopsis. Our data reveal a novel facet of auxins produced by fungi in promoting plant health, which may lead to potential applications in agriculture.

\section{MATERIALS AND METHODS}

\section{Plant material and growth conditions.}

A. thaliana was used in this work. The transgenic and mutant lines were derived from the parental Arabidopsis ecotype Columbia-0 (Col-0). The lines auxl-7 (Picket et al. 1990), eirl-1 (Roman et al. 1995), arf7arf19 (Okushima et al. 2007), and tirlafb2afb3 (Dharmasiri et al. 2005) are auxin-related mutants defective on auxin transporters AUX1 or PIN2 or affected in the transcription factors ARF7 and ARF19 or auxin receptors TIR1, AFB2, and AFB3, respectively. DR5:uidA is an auxin responsive marker (Ulmasov et al. 1997). Seed were surface sterilized with ethanol for $5 \mathrm{~min}$ and $20 \%$ (vol/vol) bleach for $7 \mathrm{~min}$. After five washes in distilled water, seed were germinated and grown on agar plates containing $0.2 \times \mathrm{MS}$ medium (Murashige and Skoog basal salts mixture, catalog number M5524; Sigma-Aldrich, St. Louis). Plates were placed vertically at a $65^{\circ}$ angle to allow root growth along the agar surface and unimpeded aerial growth of the hypocotyls. Plants 
were grown at $24^{\circ} \mathrm{C}$ in a chamber with a photoperiod of $16 \mathrm{~h}$ of light $\left(200 \mu \mathrm{mol} \mathrm{m} \mathrm{m}^{-1}\right)$ and $8 \mathrm{~h}$ of darkness.

\section{Fungal growth and plant inoculation experiments.}

The following fungal strains were used in this work: T. virens Gv29.8 and T. atroviride (formerly T. harzianum) IMI 206040. Fungal strains were grown in $0.2 \times$ MS medium with (50 to $300 \mathrm{mM} \mathrm{NaCl}$ ) or without salt (catalog number 11830-031; Gibco BRL, Bethesda, MD, U.S.A.). T. virens and T. atroviride were evaluated in vitro for their ability to promote salt tolerance in Arabidopsis. Fungal spore densities of $10^{6}$ spores were inoculated on $0.2 \times \mathrm{MS}$ medium with $100 \mathrm{mM} \mathrm{NaCl}$ or without salt by placing the spores at $5 \mathrm{~cm}$ in the opposite ends of agar plates containing 4-day-old germinated Arabidopsis seedlings (10 seedlings/plate). Plates were arranged in a completely randomized design. The seedlings were cultivated in a Percival AR95L growth chamber.

\section{Quantification of shoot and root growth.}

For shoot diameter quantification, seedlings were photographed 9 days after the treatments using a stereoscopic microscope (Leica MZ6; Leica Microsystems, Ryswyk, The Netherlands). Measurements were determined by using the Image $\mathbf{J}$ software. Growth of primary roots was registered using a ruler. LR numbers were determined by counting the LR present in the primary root. LR densities were determined by dividing the LR number by the primary root length. $\mathrm{RH}$ were measured in a $500-\mu \mathrm{m}$ region at a $1-\mathrm{cm}$ distance from the primary root tip. The average length of RH was determined by measuring 100 hairs for each root, taking as a reference the root protoxylematic plane to locate the radical hair base in the epidermal cell.

\section{Chlorophyll content measurement.}

Chlorophyll content was determined from excised Arabidopsis shoots 5 days after fungal inoculation. Shoots were homogenized in $1 \mathrm{ml}$ of $80 \%$ aqueous acetone. Chlorophyll from different samples was extracted by $48 \mathrm{~h}$ in darkness at $-20^{\circ} \mathrm{C}$. Supernatant readings were taken at 647 and $663 \mathrm{~nm}$. Total chlorophyll content was calculated as $(7.15 \times \mathrm{A} 663)+(18.71 \times$ A647) divided by $1,000 \times$ shoot fresh weight and was reported as milligrams of chlorophyll per gram of fresh weight, as described by Zhang and associates (2008b).

\section{Root exudate collection and $\mathrm{Na}^{+}$content measurement.}

Arabidopsis WT (Col-0) plants were grown as described above and root exudates from 40 seedlings per sample were collected. Five days after fungal inoculation, seedlings were transferred to falcon tubes containing tri-distilled water supplemented with $0.2 \times$ sucrose and placed at $24^{\circ} \mathrm{C}$ in a chamber with a photoperiod of $16 \mathrm{~h}$ of light $\left(200 \mu \mathrm{mol} \mathrm{m} \mathrm{m}^{-1}\right)$ and $8 \mathrm{~h}$ of darkness. Root exudates were collected 2 days later. Each treatment consisted of three replicates and each replicate consisted of a total volume of $4 \mathrm{ml}$ of exudate. The collected root exudates were filtered using nylon filters (Econofilter 25/0.45 $\mu \mathrm{m}$; Agilent Technologies Netherlands BV, Amsterdam) to remove root-border cells. After filtration, the exudates were stored at $-72{ }^{\circ} \mathrm{C}$ for further analyses. Next, aqueous $\mathrm{Na}^{+}$was determined by atomic absorption spectrophotometry (Model AAnalyst 200; Perkin Elmer, Norwalk, CT, U.S.A.).

\section{L-Pro determination.}

L-Pro extraction and determination were performed in Arabidopsis (ecotype Col-0) seedlings at 5 days after inoculation. For sample preparation, plant tissues were frozen and ground in liquid $\mathrm{N}_{2}$. Approximately $250 \mathrm{mg}$ of ground tissue was placed in an Eppendorf tube. Tissue was homogenized with $1 \mathrm{ml}$ of $0.7 \%$ (vol/vol) concentrated $\mathrm{HCl}$ in methanol and shaken for $5 \mathrm{~min}$. Samples were centrifuged at 11,500 rpm for $3 \mathrm{~min}$, and supernatants were collected and evaporated under a stream of gaseous nitrogen. L-Pro was derivatized with acetyl chloride in methanol $(500 \mu \mathrm{l}$ per $2 \mathrm{ml})$, sonicated for $25 \mathrm{~min}$, and heated for $1 \mathrm{~h}$ at $75^{\circ} \mathrm{C}$. After cooling, the methylated sample was evaporated and added to acetic anhydride $(1.5 \mathrm{ml})$ and dichloromethane $(1 \mathrm{ml})$, sonicated for $25 \mathrm{~min}$, and heated for $1 \mathrm{~h}$ at $75^{\circ} \mathrm{C}$. After cooling, the derivatized sample was evaporated and redissolved in $50 \mu \mathrm{l}$ of methanol for gas chromatography mass spectrometry (GC-MS) analysis. GC-selected ion-monitoring mass spectrometry (GC-SIM-MS) and retention time were established for N-acetyl-proline methyl ester $(\mathrm{m} / \mathrm{z}, 70$, 112 and $171 \mathrm{M}^{+}, 4.62 \mathrm{~min}$ ), respectively. L-Pro (Merck, Amsterdam) was derived and used as pure standard. To estimate the amount of L-pro in Arabidopsis seedlings, we constructed a standard curve.

\section{ABA and AA determinations.}

ABA and AA were extracted and determined in Arabidopsis (Col-0) 5 days after Trichoderma spp. inoculation. Plant tissues were frozen and ground in liquid $\mathrm{N}_{2}$. Approximately $200 \mathrm{mg}$ of ground tissue was placed in an Eppendorf tube, homogenized with $500 \mu \mathrm{l}$ of isopropanol/ $\mathrm{H}_{2} \mathrm{O} /$ concentrated $\mathrm{HCl}$ (2:1:0.002, $\mathrm{vol} / \mathrm{vol}$ ), and shaken for $30 \mathrm{~s}$. Samples were centrifuged at $11,500 \mathrm{rpm}$ for $3 \mathrm{~min}$, and supernatants were collected and subjected to ABA or AA extraction with $300 \mu \mathrm{l}$ of dichloromethane. ABA was derivatized with acetyl chloride in methanol $(500 \mu \mathrm{l}$ per $2 \mathrm{ml})$, sonicated for $15 \mathrm{~min}$, and heated for $1 \mathrm{~h}$ at $75^{\circ} \mathrm{C}$. After cooling, the derivatized sample was evaporated and resuspended in $25 \mu \mathrm{l}$ of ethyl acetate for GC-MS analysis. GC-SIM-MS and retention time were established for cis, trans-ABA methyl ester (ABA-ME; $m / z, 134,190$, and $278 \mathrm{M}^{+}$, $15.51 \mathrm{~min})$; cis, trans-ABA was purchased from SigmaAldrich and used as standard.

AA was derivatized with acetic anhydride and dichloromethane $(1.5 \mathrm{ml}$ per $1.0 \mathrm{ml})$, sonicated for $25 \mathrm{~min}$, and heated for $1 \mathrm{~h}$ at $75^{\circ} \mathrm{C}$. After cooling, the derivatized sample was evaporated and redissolved in $25 \mu \mathrm{l}$ of ethyl acetate for GCMS analysis. GC-SIM-MS and retention time were established for AA and 2, 3, 5, 6-tetra-acetyl ester $\left(\mathrm{m} / z, 200\right.$ and $344 \mathrm{M}^{+}$, $14.79 \mathrm{~min}$ ) respectively. $\mathrm{L}(+)$ AA was obtained from Merck, derivatized, and used as standard.

The identity of each compound was further confirmed by comparison with the pure standard and, to estimate the amount, we constructed an independent standard curve.

\section{IAA determination and GC-MS analysis.}

For the production of IAA, an active inoculum of $1 \times 10^{6}$ spores of T. virens or T. atroviride was added to $200 \mathrm{ml}$ of potato dextrose broth (Fluka Analytical; Sigma-Aldrich) and grown for 3 days at $24^{\circ} \mathrm{C}$, with shaking at $180 \mathrm{rpm}$. To evaluate the effect of salt supply on IAA production, the medium was supplemented or not with $\mathrm{NaCl}$ at a concentration of 100 $\mathrm{mM}$. The fungal cultures were filtered and the supernatant was adjusted to $\mathrm{pH} 3$ using $1 \mathrm{~N} \mathrm{HCl}$. IAA in supernatant solution was extracted two times with $500 \mathrm{ml}$ of ethyl acetate. The extracts were combined and evaporated to dryness under a stream of nitrogen and then diluted in $1 \mathrm{ml}$ of ethyl acetate. IAA was methyl esterified with $500 \mathrm{ml}$ of acetyl chloride in 2 $\mathrm{ml}$ of dry methanol, sonicated for $15 \mathrm{~min}$, and heated at $75^{\circ} \mathrm{C}$ for $1 \mathrm{~h}$. IAA content was determined as described previously (Contreras-Cornejo et al. 2009).

Samples were injected in an Agilent 6850 Series II gas chromatograph equipped with an Agilent MS detector model 5973 and $30-\mathrm{m}$ by $0.2-\mu \mathrm{m}$ by $0.25-\mathrm{mm}, 5 \%$ phenyl methyl silicone capillary column (HP-5 MS). The operating conditions used 
were helium at $1 \mathrm{ml} / \mathrm{min}^{-1}$ as carrier gas, $300^{\circ} \mathrm{C}$ detector temperature, and $250^{\circ} \mathrm{C}$ injector temperature. The column was held for $5 \mathrm{~min}$ at $150^{\circ} \mathrm{C}$ and programmed at $5^{\circ} \mathrm{C} \min ^{-1}$ to a $278^{\circ} \mathrm{C}$ final temperature for $5 \mathrm{~min}$.

Histochemical analysis and GUS expression measurements.

Transgenic plants that expressed the uidA reporter gene (Jefferson et al. 1987) were incubated $10 \mathrm{~h}$ at $37^{\circ} \mathrm{C}$ in GUS reaction buffer (5-bromo-4-chloro-3-indolyl- $\beta$-D-glucuronide at $0.5 \mathrm{mg} / \mathrm{ml}$ in $100 \mathrm{mM}$ sodium phosphate, $\mathrm{pH} 7)$. The stained seedlings were cleared using the method of Malamy and Benfey (1997). For each treatment, at least 15 transgenic plants were analyzed. The processed seedlings were included in glass slips and sealed with commercial nail varnish. For each treatment, a representative plant was chosen and photographed using a Leica MZ6 stereomicroscope.

GUS expression was determined in primary root tips of 9day-old Arabidopsis seedlings grown, stained, and cleared as described above. Fifteen obtained images were processed using the Image $\mathbf{J}$ software and the data expressed as arbitrary units.

\section{Data analysis.}

Experiments were statistically analyzed in the SPSS 10 program (SPSS, Chicago). Multivariate analyzes with a Tukey's post hoc test was used for testing differences in the fresh and dry weight, shoot length, chlorophyll content, ABA, L-Pro, AA, aqueous $\mathrm{Na}^{+}$, and RSA. Different letters are used to indicate means that differ significantly $(P \leq 0.05)$.

\section{ACKNOWLEDGMENTS}

We thank B. V. Castañeda for his support and technical improvement for $\mathrm{Na}^{+}$determination and T. Guilfoyle for kindly providing us with Arabidopsis transgenic seed. This work was supported by grants from the Consejo Nacional de Ciencia y Tecnología (CONACYT, México, grant number 177775), the Consejo de la Investigación Científica (UMSNH, México, grant number CIC 2.26), and the Marcos Moshinsky Foundation. H. A. Contreras-Cornejo is indebted to CONACYT for a doctoral fellowship.

\section{LITERATURE CITED}

Abogadallah, G. M. 2010. Antioxidative defense under salt stress. Plant Signal. Behav. 5:369-374.

Achard, P., Cheng, H., De Grauwe, L., Decat, J., Schoutteten, H., Moritz, T., Van Der Straeten, D., Peng, J., and Harberd, N. P. 2006. Integration of plant responses to environmentally activated phytohormonal signals. Science 311:91-94.

Bais, H. P., Weir, T. L., Perry, L. G., Gilroy, S., and Vivanco, J. M. 2006. The role of root exudates in rhizosphere interactions with plants and other organisms. Annu. Rev. Plant Biol. 57:233-66.

Bao, F., and Li, J. Y. 2002. Evidence that the auxin signaling pathway interacts with plant stress response. Acta Bot. Sin. 44:532-536.

Ben, H. A., Ghanem, M. E., Bouzid, S., and Lutts, S. 2008. An inland and a coastal population of the Mediterranean xero-halophyte species Atriplex halimus L. differ in their ability to accumulate proline and glycinebetaine in response to salinity and water stress. J. Exp. Bot. 59:1315-1326.

Brotman, Y., Landau, U., Cuadros-Inostroza, Á., Tohge, T., Fernie, A. R., Chet, I., Viterbo, A., and Willmitzer, L. 2013. Trichoderma-plant root colonization: Escaping early plant defense responses and activation of the antioxidant machinery for saline stress tolerance. PLoS Pathog. 9:e1003221. Published online.

Casimiro, I., Beeckman, T., Graham, N., Bhalerao, R., Zhang, H., Casero, P., Sandberg, G., and Bennett, M. J. 2003. Dissecting Arabidopsis lateral root development. Trends Plant Sci. 8:165-171.

Contreras-Cornejo, H. A., Macías-Rodríguez, L., Cortés-Penagos, C., and López-Bucio, J. 2009. Trichoderma virens, a plant beneficial fungus, enhances biomass production and promotes lateral root growth through an auxin-dependent mechanism in Arabidopsis. Plant Physiol. 149:1579-1592.

Contreras-Cornejo, H. A., Macías-Rodríguez, L., Beltrán-Peña, E., HerreraEstrella, A., and López-Bucio, J. 2011. Trichoderma-induced plant immunity likely involves both hormonal and camalexin dependent mechanisms in Arabidopsis thaliana and confers resistance against necrotrophic fungi Botrytis cinerea. Plant Signal. Behav. 6:1554-1563.

Contreras-Cornejo, H. A., Ortiz-Castro, R., and López-Bucio, J. 2013. Promotion of plant growth and the induction of systemic defence by Trichoderma: Physiology, genetics and gene expression. Pages 175-196 in: Trichoderma Biology and Applications. P. K. Mukherjee, ed. CABI, London.

Coudert, Y., Périn, C., Courtois, B., Khong, N. G., and Gantet, P. 2010. Genetic control of root development in rice, the model cereal. Trends Plant Sci. 15:219-226.

Dharmasiri, N., Dharmasiri, S., Weijers, D., Lechner, E., Yamada, M., Hobbie, L., Ehrismann, J. S., Jürgens, G., and Estelle, M. 2005. Plant development is regulated by a family of auxin receptor $\mathrm{F}$ box proteins. Dev. Cell 9:109-119.

Dubrovsky, J. G., Sauer, M., Napsucialy-Mendivil, S., Ivanchenko, M.G. Friml, J., Shishkova, S., Celenza, J., and Benková, E. 2008. Auxin acts as a local morphogenetic trigger to specify lateral root founder cells. Proc. Natl. Acad. Sci. U.S.A. 105:8790-8794.

Essah, P. A., Davenport, R., and Tester, M. 2003. Sodium influx and accumulation in Arabidopsis. Plant Physiol. 133:307-318.

Fabro, G., Kovács, I., Pavet, V., Szabados, L., and Alvarez, M. E. 2004. Proline accumulation and AtP5CS2 gene activation are induced by plant-pathogen incompatible interactions in Arabidopsis. Mol. PlantMicrobe Interact. 17:343-350.

Felten, J., Martin, F., and Legue, V. 2012. Signalling in ectomycorrhizal symbiosis. Signal. Commun. Plants 10:123-142.

Galvan-Ampudia, C. S., and Testerink, C. 2011. Salt stress signals shape the plant root. Curr. Opin. Plant Biol. 14:296-302.

Ghoulam, C., Foursy, A., and Fares, K. 2002. Effects of salt stress on growth, inorganic ions and proline accumulation in relation to osmotic adjustment in five sugar beet cultivars. Environ. Exp. Bot. 47:39-50.

Halperin, S. J., Gilroy, S., and Lynch, J. P. 2003. Sodium chloride reduces growth and cytosolic calcium, but does not affect cytosolic $\mathrm{pH}$, in root hairs of Arabidopsis thaliana L. J. Exp. Bot. 54:1269-1280.

Hariadi, Y., Marandon, K., Tian, Y., Jacobsen, S. E., and Shabala, S. 2011. Ionic and osmotic relations in quinoa (Chenopodium quinoa Willd.) plants grown at various salinity levels. J. Exp. Bot. 62:185-193.

Harman, G. E., Howell, C. R., Viterbo, A., Chet, I., and Lorito, M. 2004. Trichoderma species: Opportunistic, avirulent plant symbionts. Nat. Rev. Microbiol. 2:43-56.

Hilbert, M., Lars, M., Yi, D., Hofmann, J., Sharma, M., and Zuccaro, A. 2012. Indole derivative production by the root endophyte Piriformospora indica is not required for growth promotion but for biotrophic colonization of barley roots. New Phytol. 196:520-34.

Himanen, K., Boucheron, E., Vaneste, S., de Almedida-Engler, J., Inzé. D., and Beeckman, T. 2002. Auxin-mediated cell cycle activation during early lateral root initiation. Plant Cell 14:2339-2351.

Hochholdinger, F., and Tuberosa, R. 2009. Genetic and genomic dissection of maize root development and architecture. Curr. Opin. Plant Biol. 12:172-177.

Jefferson, R. A., Kavanagh, T. A., and Bevan, M. W. 1987. GUS fusion: $\beta$ glucuronidase as a sensitive and versatile fusion marker in higher plants. EMBO (Eur. Mol. Biol. Organ.) J. 6:3901-3907.

Katori, T., Ikeda, A., Iuchi, S., Kobayashi, M., Shinozaki, K., Maehashi, K., Sakata, Y., Tanaka, S., and Taji, T. 2010. Dissecting the genetic control of natural variation in salt tolerance of Arabidopsis thaliana accessions. J. Exp. Bot. 61:1125-1138.

Laskowski, M. J., Williams, M. E., Nusbaum, H. C., and Sussex, I. M. 1995. Formation of lateral root meristems is a two-stage process. Development 121:3303-3310.

Leyser, O. 2006. Dynamic integration of auxin transport and signalling. Curr. Biol. 16:424-433.

Ljung, K., Hull, A. K., Kowalczyk, M., Marchant, A., Celenza, J., Cohen, J. D., and Sandberg, G. 2002. Biosynthesis, conjugation, catabolism and homeostasis of indole-3-acetic acid in Arabidopsis thaliana. Plant Mol. Biol. 49:249-272.

López-Bucio, J., Cruz-Ramírez, A., and Herrera-Estrella, L. 2003. The role of nutrient availability in regulating root architecture. Curr. Opin. Plant Biol. 6:280-287.

López-Bucio, J., Cruz-Ramírez, A., Pérez-Torres, A., Ramírez-Pimentel, J. G., Sánchez-Calderón, L., and Herrera-Estrella, L. 2005. Root architecture. Pages 181-206 in: Plant Architecture and Its Manipulation. C. Turnbull, ed. Blackwell Annual Review Series, Oxford.

Malamy, J. E., and Benfey, P. N. 1997. Organization and cell differentiation in lateral roots of Arabidopsis thaliana. Development 124:33-44.

Mehlmer, N., Wurzinger, B., Stael, S., Hofmann-Rodrigues, D., Csaszar, E., Pfister, B., Bayer, R., and Teige, M. 2010. The $\mathrm{Ca}^{2+}$-dependent protein kinase CPK3 is required for MAPK-independent salt-stress acclimation in Arabidopsis. Plant J. 63:484-498. 
Mittler, R. 2002. Oxidative stress, antioxidants and stress tolerance. Trends Plant Sci. 7:405-410.

Mockaitis K., and Estelle M. 2008. Auxin receptors and plant development: A new signaling paradigm. Annu. Rev. Cell. Dev. Biol. 24:55-80.

Okushima, Y., Fukaki, H., Onoda, M., Theologis, A., and Tasaka, M. 2007. ARF7 and ARF19 regulate lateral root formation via direct activation of LBD/ASL genes in Arabidopsis. Plant Cell 19:118-130.

Ortíz-Castro, R., Díaz-Pérez, C., Martínez-Trujillo, M., del Rio, R. E., Campos-Garcia, J., and Lopez-Bucio, J. 2011. Transkingdom signaling based on bacterial cyclodipeptides with auxin activity in plants, Proc. Natl. Acad. Sci. U.S.A. 108:7253-7258.

Parida, A. K., Dagaonkar, V. S., Phalak, M. S., and Aurangabadkar, L. P. 2008. Differential responses of the enzymes involved in proline biosynthesis and degradation in drought tolerant and sensitive cotton genotypes during drought stress and recovery. Acta Physiol. Plant. 30:619627.

Pérez-Torres, C. A., López-Bucio, J., Cruz-Ramírez, A., Ibarra-Laclette, E., Dharmasiri, S., Estelle, M., and Herrera-Estrella, L. 2008. Phosphate availability alters lateral root development in Arabidopsis by modulating auxin sensitivity via a mechanism involving the TIR1 auxin receptor. Plant Cell 20:3258-3272.

Picket, F. B., Wilson, A. K., and Estelle, M. 1990. The auxl mutation of Arabidopsis confers both auxin and ethylene resistance. Plant Physiol. 94:1462-1466.

Rawat, L., Singh, Y., Shukla, N., and Kumar, J. 2011. Alleviation of the adverse effects of salinity stress in wheat (Triticum aestivum L.) by seed biopriming with salinity tolerant isolates of Trichoderma harzianum. Plant Soil 347:387-400.

Redman, R. S., Kim, Y. O., Woodward, C. J., Greer, C., Espino, L., Doty, S. L., and Rodriguez, R. J. 2011. Increased fitness of rice plants to abiotic stress via habitat adapted symbiosis: A strategy for mitigating impacts of climate change. PLoS One 6:e14823. Published online.

Roman, G., Lubarsky, B., Kieber, J. J., Rothenberg, M., and Ecker, J. R. 1995. Genetic analysis of ethylene signal transduction in Arabidopsis thaliana: Five novel mutant loci integrated into a stress response pathway. Genetics 139:1393-1409.

Sadeghi, A., Karimi, E., Dahaji, P. A., Javid, M. G., Dalvand, Y., and Askari, H. 2012. Plant growth promoting activity of an auxin and siderophore producing isolate of Streptomyces under saline soil conditions. World J. Microbiol. Biotechnol. 28:1503-1509.

Seki, M., Kamei, A., Yamaguchi-Shinozaki, K., and Shinozaki, K. 2003. Molecular responses to drought, salinity and frost: Common and different paths for plant protection. Curr. Opin. Biotechnol. 14:194-199.

Shabala, S., and Cuin, T. A. 2008. Potassium transport and plant salt tolerance. Physiol. Plant. 133:651-669.

Smirnoff, N. 2000. Ascorbic acid: Metabolism and functions of a multifaceted molecule. Curr. Opin. Plant Biol. 3:229-235.

Ulmasov, T., Murfett, J., Hagen, G., and Guilfoyle, T. J. 1997. Aux/IAA proteins repress expression of reporter genes containing natural and highly active synthetic auxin response elements. Plant Cell 9:19631971 .

Ungar, I. 1996. Effect of salinity on seed germination, growth, and ion accumulation of Atriplex patula (Chenopodiaceae). Am. J. Bot. 83:604-607.

Velázquez-Robledo, R., Contreras-Cornejo, H. A., Macías-Rodríguez, L., Hernández-Morales, A., Aguirre, J., Casas-Flores, S., López-Bucio, J., and Herrera-Estrella, A. 2011. Role of the 4-phosphopantetheinyl transferase of Trichoderma virens in secondary metabolism, and induction of plant defense responses. Mol. Plant-Microbe Interact. 24:1459-1471.

Verslues, P. E., and Zhu, J. K. 2005. Before and beyond ABA: Upstream sensing and internal signals that determine ABA accumulation and response under abiotic stress. Biochem. Soc. Trans. 33:375-379.

Waller, F., Achatz, B., Baltruschat, H., Fodor, J., Becker, K., Fischer, M., Heier, T., Hückelhoven, R., Neumann, C., von Wettstein, D., Franken, P., and Kogel, K. H. 2005. The endophytic fungus Piriformospora indica reprograms barley to salt-stress tolerance, disease resistance, and higher yield. Proc. Natl. Acad. Sci. U.S.A. 102:13386-13391.

Wang, Y., Li, K., and Li. X. 2009. Auxin redistribution modulates plastic development of root system architecture under salt stress in Arabidopsis thaliana. J. Plant Physiol. 166:1637-1645.

Waqas, M., Khan, A. L., Kamran, M., Hamayun, M., Kang, S. M, Kim, Y. H., and Lee, I. J. 2012. Endophytic fungi produce gibberellins and indole-acetic acid and promotes host-plant growth during stress. Molecules 17:10754-10773.

Wasilewska, A., Vlad, F., Sirichandra, C., Redko, Y., Jammes, F., Valon, C., Frei dit Frey, N., and Leung, J. 2008. An update on abscisic acid signaling in plants and more. Mol. Plant. 1:198-217.

Woodward, A. W., and Bartel, B. 2005. Auxin: Regulation, action, and interaction. Ann. Bot. (Lond.) 95:707-735.

Xiong, L., Lee, H., Ishitani, M., and Zhu, J.K. 2002a. Regulation of osmotic stress-responsive gene expression by the LOS6/ABA1 locus in Arabidopsis. J. Biol. Chem. 277:8588-8596.

Xiong, L., Schumaker, K. S., and Zhu, J. K. 2002b. Cell signaling during cold, drought, and salt stress. Plant Cell (Suppl.) 14:S165-S183.

Zhang, H., Kim, M. S., Sun, Y., Dowd, S. E., Shi, H., and Paré, P. W. 2008a. Soil bacteria confer plant salt tolerance by tissue-specific regulation of the sodium transporter HKT1. Mol. Plant-Microbe Interact. 21:737-744.

Zhang, H., Xie, X., Kim, M. S., Kornyeyev, D. A., Holaday, S., and Paré P. W. 2008b. Soil bacteria augment Arabidopsis photosynthesis by decreasing glucose sensing and abscisic acid levels in planta. Plant $\mathbf{J}$. 56:264-273.

Zhu, J. K. 2003. Regulation of ion homeostasis under salt stress. Curr. Opin. Plant Biol. 6:441-445.

Zörb, C., Geilfus, C. M., Mühling, K. H., and Ludwig-Müller, J. 2013. The influence of salt stress on ABA and auxin concentrations in two maize cultivars differing in salt resistance. J. Plant Physiol. 170:220-234. 